\title{
Solidification Morphology and Bifurcation Predictions with the Maximum Entropy Production Rate Model
}

\author{
Yaw Delali Bensah ${ }^{1}$ (i) and J. A. Sekhar ${ }^{2, *}$ \\ 1 Department of Materials Science and Engineering, University of Ghana, Legon, Accra P.O. Box LG 77, \\ Ghana; bensahyad@gmail.com \\ 2 Department of Mechanical and Materials Engineering, University of Cincinnati, Cincinnati, OH 45221, USA \\ * Correspondence: Jainagesh.sekhar@uc.edu
}

Received: 30 October 2019; Accepted: 18 December 2019; Published: 26 December 2019

\begin{abstract}
The use of the principle of maximum entropy generation per unit volume is a new approach in materials science that has implications for understanding the morphological evolution during solid-liquid interface growth, including bifurcations with or without diffuseness. A review based on a pre-publication arXiv preprint is first presented. A detailed comparison with experimental observations indicates that the Maximum Entropy Production Rate-density model (MEPR) can correctly predict bifurcations for dilute alloys during solidification. The model predicts a critical diffuseness of the interface at which a plane-front or any other form of diffuse interface will become unstable. A further confidence test for the model is offered in this article by comparing the predicted liquid diffusion coefficients to those obtained experimentally. A comparison of the experimentally determined solute diffusion constant in dilute binary $\mathrm{Pb}-\mathrm{Sn}$ alloys with those predicted by the various solidification instability models (1953-2011) is additionally discussed. A good predictability is noted for the MEPR model when the interface diffuseness is small. In comparison, the more traditional interface break-down models have low predictiveness.
\end{abstract}

Keywords: maximum entropy production rate; MEPR; planar morphology; cellular morphology; morphological bifurcations at solid-liquid interface; growth velocity; temperature gradients; coefficient of diffusion at high temperatures

\section{Introduction}

The maximum entropy generation principle [1-16] has brought significant predictive capability to quantitative materials science. The principle has been able to reveal (a) the onset of various forms of morphological bifurcations during growth, especially the onset of the first roughening transition $[1,2,6,9]$; (b) complex solute segregation and texture reconfiguration phenomena, particularly noted during tribological contacts [4,12]; (c) Belousov-Zhabotinsky patterns and reaction pathways for high temperature reactions [2,3]; (d) the onset of steady state structures during solid-solid wear [5-8]; and (e) the stable ellipsoidal patterns that are noted in solidification microstructures (dendrite tips), multiphase fluid flows, and particle sedimentation [2,10-19]. The principle accurately predicts the trajectory of objects in motion when subjected to a gravitational field [16] and by extrapolation of the field-theory for the assessment of the efficacy of solar cells [17].

The maximum entropy production rate-density, MEPR, or the Maximum Entropy Production Principle, MEPP, are the acronyms used in the literature $[2,6,9,10]$ for analyses that employ the entropy rate maximization principle. We have chosen to use MEPR [2] in this article to emphasize the importance of the "rate" in the acronym. A MEPR hypothesis is tested in this article for initiating interface diffuseness 
or topographical changes in the two-phase and/or diffuse interface regions. Any criterion for bifurcation based on this principle is expected to be related to the composition, partition function, velocity of solidification, and the temperature gradient experienced in the solid-liquid zone $[1,2,18]$.

The MEPR model postulates that the entropy generation is maximized for an interface transition (bifurcation) to a different configuration (i.e., to a different atomistic or topographical (morphological) variant). In this article, we first review the MEPR solidification bifurcation model [1,2] and compare it with other models for the plane front instability. The model predictions are tested with the experimental data available from published studies on numerous dilute binary alloys [1]. The ensuing model for pure substance or a binary alloy has been shown to quantitatively predict the size of a diffuse interface and the number of pseudo-atomic layers present in the diffuse zone [1]. This is reviewed below. A further comparison with experimentally measured breakdown groupings of variables that have been reported in the solidification-research literature indicates that the MEPR model is also able to account for the interface topography as being either of a faceted (f) or non-faceted (n/f) kind [1]. It must be noted that model also correctly offers a quantitative measure for the transition from facet to non-facet $(\mathrm{f} / \mathrm{nf})$ planar or to a non-planar topography, as being dependent on the velocity and the temperature gradient [1]. As the entropy generation is related to the gradients, it is possible that the MEPR criterion may also allow for a better estimate of the solute diffusion constant in binary alloys [18] that has proved elusive to predict by traditional models. This hypothesis is tested for dilute $\mathrm{Pb}-\mathrm{Sn}$ alloys in this article.

When an alloy is directionally solidified at a low velocity (typically in the order of one micrometer per second), a planar morphology is first noted at the solid-liquid interface. With an increase in the transformation velocity (enabled by increasing the cooling rate or the Bridgman-Stockbarger imposed growth rate (See for example https://en.wikipedia.org/wiki/Bridgman-Stockbarger_technique), the initially planar interface becomes unstable with other shapes, transforming to a non-planar, macroscopically jagged or wavy cellular shape to the variations possible in the topography; or it may transform to a diffuse interface with non-planar shape variations [18]. There is a loss of work potential, $\mathrm{W}_{\mathrm{L}}$, with a new shape or diffuseness formation, which in turn is related to the entropy generation. The appearance of a smooth-cellular or jagged morphology from a planar interface, especially for binary alloys, depends on the material composition, $\mathrm{C}_{\mathrm{O}}\left(\mathrm{wt} \%\right.$ or mole $\left./ \mathrm{m}^{3}\right)$, velocity $\mathrm{V}(\mathrm{m} / \mathrm{s})$ of the growing interface, and the temperature gradient $\mathrm{G}_{\mathrm{L}}(\mathrm{K} / \mathrm{m})$ in the liquid and $\mathrm{k}$, the non-dimensional solute partition coefficient. These variables at the point of morphological instability are commonly subscripted with the symbol (c) to indicate a transition [18-42]. Various theoretical models [18-34] have been offered to explain the transition, however, the two most widely employed models (prior to MEPR) that describe the interface instability from planar to non-planar are the constitutional undercooling (CUT) [19-22,27] and the linear stability theory model (LST) [31]. A minimum-maximum entropy model was also previously proposed [24] but did not provide comprehensive predictability, ostensibly because the Prigogine criterion used in that model for the minimum-maximum criterion was not applicable [2]. The objective of this article is to extend the confidence in the MEPR model with comparative tests made in [1] in order to select between the models.

The CUT, LST, and MEPR models contain a diffusion parameter, namely, the coefficient of diffusion of solute in the liquid. Consequently, one additional test for the comparison of the three models is to compare the predicted values of the coefficient of diffusion to an experimental number measured from a non-solidification experiments at that temperature. In [18], it was shown that the values predicted by CUT and LST models show considerable deviation from the experimental number. In this article, comparisons with the MEPR model are made.

\section{The MEPR Model}

During the one dimensional solidification of a pure metal or a binary molten alloy, which is at freezing temperature under a fixed temperature gradient and with constant interface velocity there is a loss of work potential from the dissipation of kinetic energy, giving rise to entropy generation rate density $\dot{\varphi}_{\max }\left(\mathrm{J} \mathrm{m}^{-3} \mathrm{~K}^{-1} \mathrm{~s}^{-1}\right)$ is given by [1] in the region of the diffuse interface with dimensions 
$\zeta(\mathrm{m})$. The subscript max. indicates that that the maximum value of this new entropy generation rate is given by:

$$
\dot{\varphi}_{\max }=\frac{\Delta \rho_{\mathrm{k}} \mathrm{V}^{3}}{2 \zeta^{2} \mathrm{G}_{\mathrm{SLI}}}
$$

where $\Delta \rho_{\mathrm{k}}\left(\mathrm{kgm}^{-3}\right)$ is the overall density shrinkage given by $\left(\rho_{\mathrm{l}} \Delta \rho / \rho_{\mathrm{s}}\right), \Delta \rho\left(\mathrm{kgm}^{-3}\right)$ is the density change from liquid to solid $\left(\rho_{\mathrm{s}}-\rho_{\mathrm{l}}\right) ; \rho_{\mathrm{s}}\left(\mathrm{kgm}^{-3}\right)$ and $\rho_{\mathrm{l}}\left(\mathrm{kgm}^{-3}\right)$ are the densities of the fully solid and fully liquid zones, respectively. The symbol GSLI $\left(\mathrm{Km}^{-1}\right)$ is the temperature gradient across the solid-liquid interface, including the diffuse interface. This gradient is difficult to measure experimentally, so it is commonly approximated as the average between the rigorous-solid and rigorous-liquid regions. In this article, $\mathrm{G}_{\mathrm{SLI}}$ is assumed to be approximately equal to the temperature gradient in the fully liquid zone, $\mathrm{G}_{\mathrm{L}}\left(\mathrm{Km}^{-1}\right)$, (i.e., $\left.\mathrm{G}_{\mathrm{SLI}} \approx \mathrm{G}_{\mathrm{L}}\right)$.

At the solid-liquid interface region, during directional solidification of a binary material, the existence of diffuseness or a non-planar morphology (such as cellular) can produce new entropy. Following Sekhar [2], the entropy rate maximization in this region when compared between various morphological pathways can be thought to be somewhat analogous to the free energy selections between various phases. A cellular structure produces entropy of a positive value that increases with velocity, as does the planar diffuse structure [1,2], but at different rates. The postulate of MEPR applied to solidification morphology is that the highest entropy-rate-producing configuration is the most stable. During directional solidification (one dimensional growth in casting, as is done for turbine blades or jewelry manufacture), the first transition from a stationary planar interface is the evolution in the interface region from an atomically sharp to a diffuse interface between the rigorous solid and the rigorous liquid [2]. For an alloy, further topographical variations become possible as the entropy generation rate per unit volume reaches a peak, beyond which a cellular or other non-planar structure (e.g., cells or dendrites) can overtake the planar entropy production rate at any given composition of the alloy [1,2]. Detailed calculations for developing Equation (1) for the diffuseness dimension and the instability criterion are shown in [1]—only a brief review is provided below. The maximum entropy generation rate per unit volume (or the entropy rate density) $[1,2]$ is related to $\dot{\mathrm{s}}_{\mathrm{LG}}\left(\mathrm{J} \mathrm{m}^{-3} \mathrm{~K}^{-1} \mathrm{~s}^{-1}\right)$, which is the entropy transfer rate from the solute gradient in the liquid and $\dot{s}_{\mathrm{E}}\left(\mathrm{J} \mathrm{m}^{-3} \mathrm{~K}^{-1} \mathrm{~s}^{-1}\right)$ (i.e., the main component of the entropy generation rate that describes the entropy generated due to exchange of matter and heat in the SLI), expressed as:

$$
\dot{\varphi}_{\max }=\dot{\mathrm{s}}_{\mathrm{E}}-\dot{\mathrm{s}}_{\mathrm{LG}}
$$

$\dot{\mathrm{s}}_{\mathrm{E}}$ and $\dot{\mathrm{s}}_{\mathrm{LG}}$ are given by $\left(\mathrm{V} \Delta \mathrm{h}_{\mathrm{sl}} \mathrm{G}_{\mathrm{SLI}} / \mathrm{T}_{\mathrm{M}}^{2}\right)$ and $\left(\Delta \mathrm{T}_{\mathrm{O}} \mathrm{V}^{2} \mathrm{R}_{\mathrm{g}} \ln (1 / \mathrm{k}) / \mathrm{D}_{\mathrm{L}} 4 \mathrm{~m}_{\mathrm{L}}\right)$, respectively [1]. The term $\Delta \mathrm{h}_{\mathrm{sl}}\left(\mathrm{Jm}^{-3}\right)$ is the heat of fusion, which is an approximation for $\Delta \mathrm{h}_{\mathrm{m}}$ [2]; $\Delta \mathrm{h}_{\mathrm{m}}\left(\mathrm{Jmol}^{-1}\right)$ is the heat of fusion with defects; $\mathrm{m}_{\mathrm{L}}\left(\mathrm{Km}^{3} \mathrm{~mole}^{-1}\right)$ is the slope of the liquidus line at the solid-liquid boundary for a binary material; $\mathrm{k}$ (dimensionless) is the partition coefficient that can be obtained from the binary phase diagram; $D_{L}\left(\mathrm{~m}^{2} \mathrm{~s}^{-1}\right)$ coefficient of solute diffusion in the alloy. Here, $\Delta \mathrm{T}_{\mathrm{O}}(\mathrm{K})$ is the solidification temperature range, which is expressed as $\left(T_{1}-T_{S}\right)$ or $\left(C_{O}(1-k) m_{L} / k\right)$, where $T_{1}$ and $T_{s}$ are the liquidus and solidus temperatures, respectively, and can be obtained from the phase diagram. The conditions given by Equations ( $3 \mathrm{a}$ ) and ( $3 \mathrm{~b}$ ) below for a maximum or minimum defines a possible onset of a bifurcation condition (morphological instability).

$$
\left(\frac{\partial \dot{\varphi}_{\max }}{\partial \mathrm{V}}\right)_{\mathrm{C}_{\mathrm{O}}}=0
$$

or

$$
\left(\frac{\partial \dot{\varphi}_{\max }}{\partial \mathrm{V}}\right)_{\zeta}=0
$$


Note that arguments to indicate the maximization condition are provided in $[2,6,9,10]$. Note that $\left(\frac{\partial^{2} \dot{\varphi}_{\max }}{\partial \mathrm{V}^{2}}\right)_{\zeta, \mathrm{C}_{\mathrm{O}}}$ is negative when inferring a maximization condition. Although $\mathrm{T}_{\mathrm{si}}$ and $\mathrm{T}_{\mathrm{li}}$ are unknown based on binary alloy materials, the thickness $\zeta$ of the diffuse interface $(m)$ can be approximated for dilute solutions by assuming that $\mathrm{T}_{\mathrm{si}} \approx \mathrm{T}_{\mathrm{m}}$ and $\mathrm{T}_{\mathrm{li}} \approx \mathrm{T}_{\mathrm{m}}$, and following the procedures developed in [1], the standard solute balance at steady state growth along with Equation (3a) above can used to yield:

$$
\left(\frac{\partial \dot{\varphi}_{\max }}{\partial \mathrm{V}}\right)_{\mathrm{C}_{\mathrm{O}}}=\frac{\Delta \mathrm{h}_{\mathrm{sl}} \mathrm{G}_{\mathrm{SLI}}}{\mathrm{T}_{\mathrm{li}} \cdot \mathrm{T}_{\mathrm{si}}}-\frac{2 \Delta \mathrm{T}_{\mathrm{O}}}{\mathrm{D}_{\mathrm{L}}} \frac{\mathrm{V} \mathrm{R}_{\mathrm{g}} \ln (1 / \mathrm{k})}{4 \mathrm{~m}_{\mathrm{L}}}
$$

Here, $\mathrm{C}_{\mathrm{O}}\left(\mathrm{wt} \%\right.$ or mole $\left.\mathrm{m}^{-3}\right)$ is the solute concentration in the alloy.

Similarly, Equation (2) yields,

$$
\left(\frac{\mathrm{V}}{\mathrm{G}_{\mathrm{SLI}}}\right)_{\mathrm{C}}=\frac{\mathrm{D}_{\mathrm{L}}}{\Delta \mathrm{T}_{\mathrm{O}}} \frac{2 \mathrm{~m}_{\mathrm{L}} \Delta \mathrm{h}_{\mathrm{sl}}}{\mathrm{T}_{\mathrm{m}}^{2} \mathrm{R}_{\mathrm{g}} \ln \left(1 / \mathrm{k}_{\mathrm{eff}}\right)}
$$

Now by using ( $3 b)$ and (5), $\zeta$ can be written as:

$$
\zeta=\frac{\mathrm{V}}{\mathrm{G}_{\mathrm{SLI}}} \frac{1}{\sqrt{\mathbf{M}-\mathbf{B}}}
$$

where $\mathbf{N}\left(\mathrm{m}^{2} \mathrm{~K}^{-2} \mathrm{~s}^{-2}\right)$ is defined as $\left[\left(\frac{2 \Delta \mathrm{h}_{\mathrm{sl}}}{\Delta \rho_{\mathrm{k}} \mathrm{T}_{\mathrm{m}}^{2}}\right)-\left(\frac{\mathrm{V} \Delta \mathrm{T}_{\mathrm{O}} \mathrm{R}_{\mathrm{g}} \ln \left(\frac{1}{\mathrm{~K}_{\text {eff }}}\right)}{2 \mathrm{G}_{\mathrm{SLI}} \mathrm{D}_{\mathrm{L}} \Delta \rho_{\mathrm{k}} \mathrm{m}_{\mathrm{L}}}\right)\right], \mathbf{M}\left(\mathrm{m}^{2} \mathrm{~K}^{-2} \mathrm{~s}^{-2}\right)$ is defined as $\left(\frac{2 \Delta \mathrm{h}_{\mathrm{sl}}}{\Delta \rho_{\mathrm{k}} \mathrm{T}_{\mathrm{m}}^{2}}\right)$ and $\mathbf{B}\left(\mathrm{m}^{2} \mathrm{~K}^{-2} \mathrm{~s}^{-2}\right)$ is defined as $\left(\frac{\mathrm{V} \Delta \mathrm{T}_{\mathrm{O}} \mathrm{R}_{\mathrm{g}} \ln \left(\frac{1}{\mathrm{k}_{\text {eff }}}\right)}{2 \mathrm{G}_{\mathrm{SLI}} \mathrm{D}_{\mathrm{L}} \Delta \rho_{\mathrm{k}} \mathrm{m}_{\mathrm{L}}}\right)$.

Here, $\mathrm{k}_{\mathrm{eff}}$ is the effective partition coefficient for a diffuse interface. The equation is valid for extremely dilute alloys. Changing the formulation of Equation (6) by placing back into Equation (5) now also gives the driving force diffuseness for a binary alloy material as: $\eta_{\mathrm{G}}=\frac{\mathrm{V}}{\mathrm{G}_{\mathrm{SLI}}} \frac{1}{\mathrm{~d}} \frac{1}{\sqrt{\mathrm{N}}}$, where $\mathrm{d}$ is the interplanar lattice spacing normal to the growth direction. However, note that the exact bifurcation may occur at any velocity and temperature gradient greater than that set by Equation (5) (i.e., Equation (5) only sets one boundary condition). By analyzing the entropy generation density for a wavy interface [1], one can also infer that the interface will break down between

$$
\frac{\mathrm{D}_{\mathrm{L}}}{\Delta \mathrm{T}_{\mathrm{O}}} \frac{2 \mathrm{~m}_{\mathrm{L}} \Delta \mathrm{h}_{\mathrm{sl}}}{\mathrm{T}_{\mathrm{m}}^{2} \mathrm{R}_{\mathrm{g}} \ln \left(1 / \mathrm{k}_{\text {eff }}\right)}<\left(\frac{\mathrm{V}}{\mathrm{G}_{\mathrm{SLI}}}\right)_{\mathrm{C}}<\frac{2 \mathrm{D}_{\mathrm{L}}}{\Delta \mathrm{T}_{\mathrm{O}}} \frac{2 \mathrm{~m}_{\mathrm{L}} \Delta \mathrm{h}_{\mathrm{sl}}}{\mathrm{T}_{\mathrm{m}}^{2} \mathrm{R}_{\mathrm{g}} \ln \left(1 / \mathrm{k}_{\text {eff }}\right)}
$$

This is the MEPR condition for describing the breakdown limits. Because the condition is based on the comparison of the entropy rate maximization, it may also be recast in terms of the cooling rate $\left(\mathrm{VG}_{\mathrm{SLI}}\right)_{\mathrm{C}}$.

Note that Figure 1 establishes a relationship between the diffuseness and the break down variable. Figure 1 shows the plot of the total diffuseness as a function of $\left(\mathrm{V} / \mathrm{G}_{\mathrm{sli}}\right)_{\mathrm{c}}$. The figure plots the set of measurable breakdown parameters. For any alloy this would be a straight line as per the MEPR model. However, we note that that the band is the similar across various alloys thus highlighting the previously unanticipated relationship between interface diffuseness and the solidification parameters. This implies that the results shown below in Figures 2 and 3, namely the maximums in the entropy generation rate, are anticipated by the experiments. Additionally, the slopes are different for faceted materials when compared to the non-facet situation, possibly indicating features of diffuseness not fully captured by the MEPR model. 


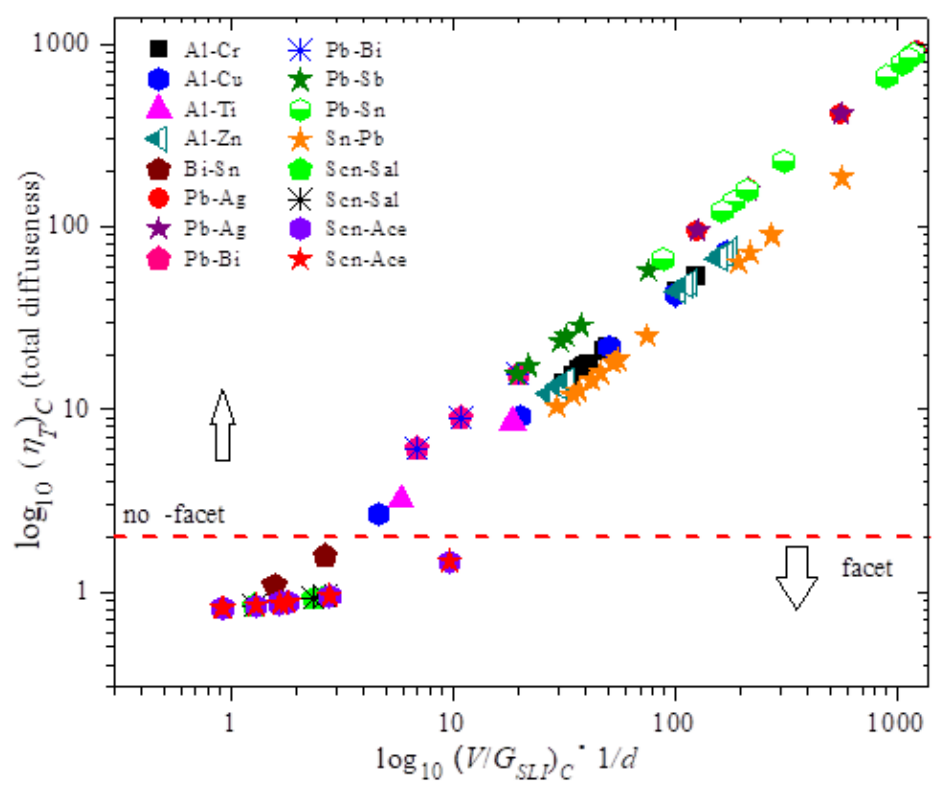

Figure 1. The plot shows measured experimental conditions at breakdown in the abscissa and calculated interface diffuseness on the ordinate. If the total interface diffuseness is greater than one or two atomic layers, then there is a possibility of non-facet morphology at breakdown, otherwise it should be facet morphology [1]. The relationship between total diffuseness and the ratio of the velocity/temperature gradient $(\mathrm{V})_{\mathrm{C}} /\left(\mathrm{G}_{\mathrm{SLI}}\right)_{\mathrm{C}}$ should yield a straight line irrespective of material parameters for any growth direction (or crystal plane spacing normal to a growth direction) in the MEPR model. The values $V$ and $G_{S L I}$ are experimentally measured numbers at breakdown, and $\eta_{\mathrm{T}}$ is calculated from the model [1]. Note that succinonitrile (SCN) alloys are non-faceted by an additional thermal and possibly rotational diffuseness at the melting temperature, which makes the SCN material transformation always appear with a non-faceted morphology particularly when observed at optical level magnifications. Experimentally, the materials shown below the dashed line $\left(\log _{10} \eta_{\mathrm{T}}=2\right)$ are recorded to be macroscopically faceted [1]. For the zone for facet materials, a different slope than in the non-facet region may represent different mechanisms for growth (e.g., nucleation-dominated or dislocation-dominated) $[22,32,43]$.

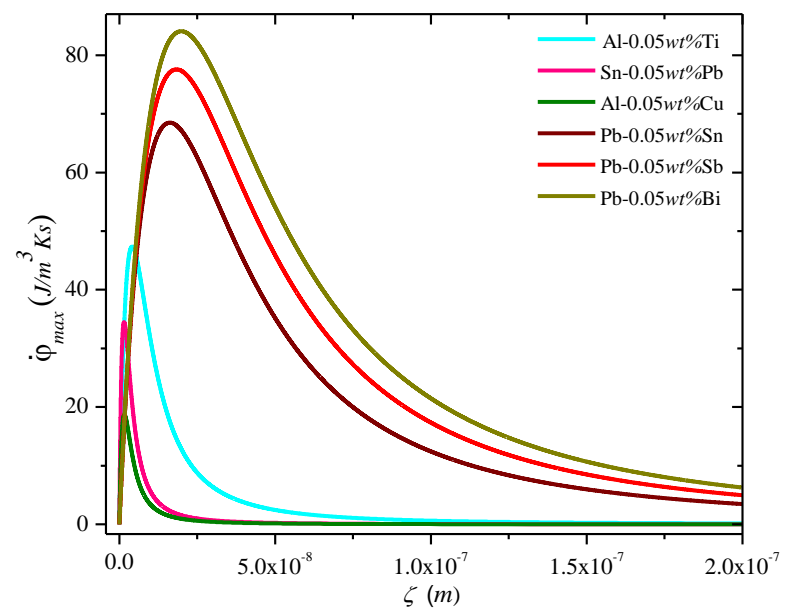

Figure 2. MEPR model prediction of the calculated maximum entropy generation rate density $\dot{\varphi}_{\max }$ $\left(\mathrm{J} / \mathrm{m}^{3} \mathrm{Ks}\right)$ against the diffuse interface thickness at a constant solute concentration for dilute binary materials. The $\dot{\varphi}_{\max }$ for the diffuse plane front reaches its highest value at the peak of the curve (i.e., when $\mathbf{M}$ becomes equal to $2 \mathbf{B}$ ). 


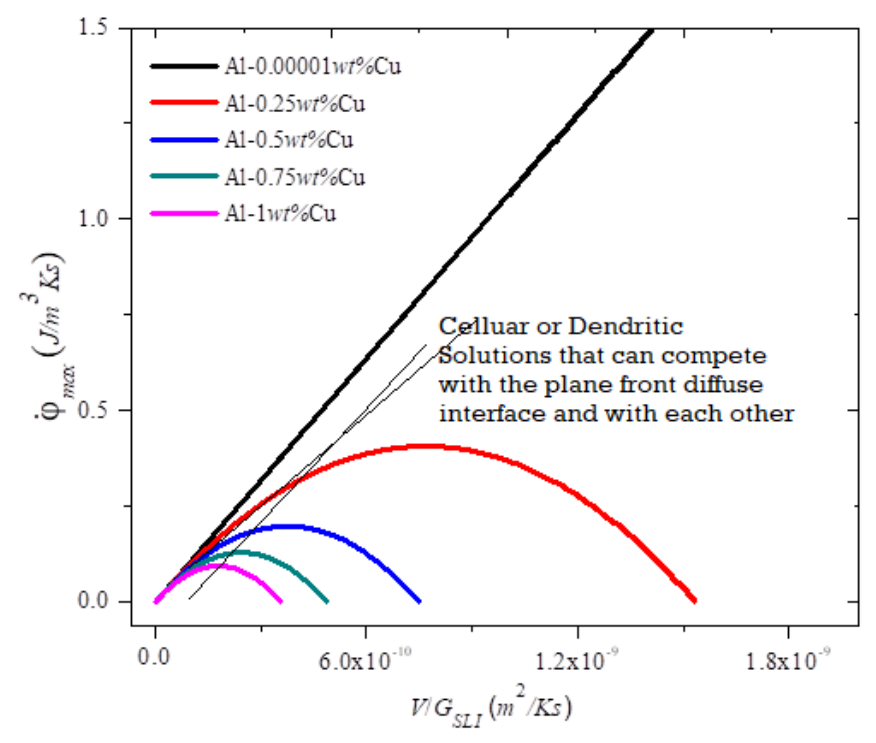

Figure 3. MEPR model prediction [1] of calculated $\dot{\varphi}_{\max }\left(\mathrm{J} / \mathrm{m}^{3} \mathrm{Ks}\right)$ as a function of the $\left(\mathrm{V} / \mathrm{G}_{\mathrm{SLI}}\right)$ for $\mathrm{Al}-\mathrm{Cu}$ with solute concentrations for five compositions (thick colored curves). The $\dot{\varphi}_{\text {max }}$ increases with decreasing solute concentration and reaches a maximum value. At extremely low solute concentration, the binary material behaves similarly to a pure material (linear dark line) and $\dot{\varphi}_{\text {max }}$ increases indefinitely with $\mathrm{V} / \mathrm{G}_{\mathrm{SLI}}$, like a pure metal [1]. Note the two thin schematic lines, one for cells (that begins at the origin) and the other for some form of dendrites, are also shown to indicate how a bifurcation transition may be reached, and further how dendrites can overtake cellular morphologies (see reference [2] for more details on types of dendrites). Note that in Equation (8) a similar graphical relationship for the entropy rate density generation density is seen when the abscissa is the cooling rate $\left(V * G_{S L I}\right)$ [1]. For unconstrained dendrites [18] the cooling rate is a preferred grouping of processing variables to indicate particularly the fineness of the secondary dendrites with increased cooling rate [32,33,43,44].

Equation (6) can be related to the processing parameters for constrained or unconstrained solidification namely, $\left(\mathrm{V} / \mathrm{G}_{\mathrm{SLI}}\right)$ or the cooling rate $\left(\mathrm{VG}_{\mathrm{SLI}}\right)$ respectively to yield the following entropy rate based criteria,

$$
\begin{gathered}
\left(\frac{\mathrm{V}}{\mathrm{G}_{\mathrm{SLI}}}\right)_{\mathrm{C}}=\frac{2}{\Delta \rho_{\mathrm{k}}}\left(\frac{\dot{\varphi}_{\max }}{\mathrm{NG}_{\mathrm{SLI}}^{2}}\right)_{\mathrm{C}} \\
\left(\mathrm{VG}_{\mathrm{SLI}}\right)_{\mathrm{C}}=\frac{2\left(\dot{\varphi}_{\max }\right)_{\mathrm{C}}}{\Delta \rho_{\mathrm{k}} \mathrm{N}_{\mathrm{C}}}
\end{gathered}
$$

where c refers to critical and $\mathrm{N}$ is defined below Equation (6) (please also see nomenclature).

Figures 2 and 3 show the plot of the entropy rate density as a function of the alloy parameters (diffuseness) and the processing and for the MEPR model. The first and second derivatives w.r.t. to $\mathrm{V}$ at constant $\zeta$ and $G_{S L I}$ indicate that the entropy generation rate will increase linearly with velocity unless solute partitioning into the liquid is allowed. When solute partitioning is possible, the entropy rate generation term indicates a maximum when plotted as a function of velocity (Figure 2). If no other interface configuration is feasible (those that display a higher entropy rate generation, such as a seaweed, jagged or fine tip interface), the interface will remain planar during growth. Note that $\dot{\varphi}_{\max }$ cannot be less than zero (second law of thermodynamics). This implies that regardless of the sign of $\mathrm{G}_{\mathrm{SLI}}$, the critical $\dot{\varphi}_{\max }$ can only have a lower value of zero for a planar interface. Thus, a non-planar shape can always overtake a plane front morphology for a negative temperature gradient, or in other words a negative temperature gradient will always imply a breakdown into cells or other patterns (unless a high-velocity-plane front transition occurs [2]). Additionally, because cellular shapes with a diffuse interface are seemingly restricted by the bounds of entropy from the diffuseness of alternate shapes, additional configurational entropy production rate increases for complex features 
(e.g., dendrites) are feasible and so will always emerge as an alternative structure unless a very wide diffuse interface topographies are possible with no partitioning. This is a possible explanation for why well-defined cellular features are not commonly noted in microstructures, such as atomized powders that solidify with a negative temperature gradient. Figures 2 and 3 show the entropy generation rate density as a function of various solidification features and collapsed parameters that are known to influence instability of a particular topography or morphology. Note the definitions of $\mathbf{B}, \mathbf{M}$, and $\mathbf{N}$ from Equations (4)-(6) and the nomenclature. When $\mathbf{B}$ becomes greater than or equal to $\mathbf{M}$, then $\mathbf{N}$ is either zero or negative; consequently, the interface diffuseness becomes undefined. The maximum entropy generation rate density increases with the corresponding increase in diffuse interface thickness and falls only when the parameter $\mathbf{B}$ approaches $0.5 \mathbf{M}$. The growth of the interface can be steady when $\mathbf{N}$ is greater than one. When the temperature gradient is zero, the diffuse interface thickness becomes undefined, thus allowing $k_{\text {eff }}$ to take on a high value closer to one. When $\mathbf{B}$ is equal to $\mathbf{M}$, then $\mathbf{N}$ is zero, and $\zeta$ and $\dot{\varphi}_{\max }$ are both undefined. From the transition instability criterion defined above, the peak for $\dot{\varphi}_{\max }$ against velocity occurs when $\mathbf{M} / \mathbf{B}$ (dimensionless) is equal to 2 (i.e., $\mathbf{M} / \mathbf{N}^{0.5}$ ) is equal to $\left(\frac{2 \Delta \mathrm{h}_{\mathrm{sl}}}{\Delta \rho_{\mathrm{k}} \mathrm{T}_{\mathrm{m}}^{2}}\right)$. Figure 2 in [1] shows the plot of the entropy generation rate as a function of the diffuseness. When $\mathbf{M}>\mathbf{B}$, then the number of pseudo-atomic layers present within the diffuse interface region is easily related to the driving force diffuseness in an almost linear manner [1]. Note that the deviation from linearity sets in at a lower $V / G_{S L I}$ as the concentration increases. At the condition where $\mathbf{M} \geq \mathbf{N}>1$, noted in Figure 2, a steady slope is observed, where the $V / G_{S L I}$ ratio shows a strong effect on the number of pseudo-atomic-spacings [1]. As the condition for $1>\mathbf{N}>0$ is encountered, even a small change in the $\mathrm{V} / \mathrm{G}_{\mathrm{SLI}}$ ratio can lead to a rapid change in the number of pseudo-atomic spacings at the interface. Figure 3 shows the parabolic-like profile of the entropy generation rate density as a function of $V / G_{\text {sli }}$. Both Figures 2 and 3 indicate that a peak is noted in the entropy generation rate density for a planar interface, essentially giving other entropy producing morphologies a possibility to dominate over the plane front structure (whether diffuse or not). An example is shown in Figure 3 of how the entropy rate for a cellular pattern or a dendritic morphology may indicate transitions to those shapes. Note that an implication of the results in Figure 1 is that $\Delta \mathrm{T}_{\mathrm{SLI}}$ approaches $\Delta \mathrm{T}_{\mathrm{O}}$, but a morphological transition prevents the full attainment for this separation for the plane front (i.e., if the high velocity plane front condition is not encountered) [2,13,38-40].

\section{Traditional Instability Models}

\subsection{The CUT Model}

The first interface breakdown model was proposed qualitatively by Rutter and Chalmers [22], and then quantitatively described by Tiller, Rutter, Jackson, and Chalmers [19]. This model describes the interface instability (from planar to non-planar) as being enabled by a region of constitutionally undercooled liquid that forms ahead of the solid-liquid interface during growth from solute partitioning. For a binary alloy, the CUT criterion for instability is written as:

$$
\mathrm{D}_{\mathrm{L}}=\left(\frac{\mathrm{V}}{\mathrm{G}_{\mathrm{L}}}\right)_{\mathrm{C}} \Delta \mathrm{T}_{\mathrm{O}}
$$

where $G_{L}\left(\mathrm{Km}^{-1}\right)$ is the temperature gradient in the liquid, $\mathrm{D}_{\mathrm{L}}\left(\mathrm{m}^{2} \mathrm{~s}^{-1}\right)$ is the solute diffusion coefficient in the liquid, and $\Delta T_{O}(K)$ is the equilibrium solidification range $\left(T_{1}-T_{S}\right)$ for a liquid at composition $\mathrm{C}_{\mathrm{O}}\left(\right.$ molem $\left.^{-3}\right)$. Also, $\mathrm{T}_{1}(\mathrm{~K})$ and $\mathrm{T}_{\mathrm{S}}(\mathrm{K})$ are the equilibrium liquidus and solidus temperatures captured in equilibrium phase diagrams.

\subsection{The LST Model}

In 1964, Mullins and Sekerka [31] proposed the linear stability model (LST) that considered the stability of a planar interface to a perturbation of an infinitesimal amplitude. In this stability model, 
the interface is unstable if any wavelength of a sinusoidal perturbation grows, and conversely the interface is stable if none of the perturbations can grow (regardless of their wavelength and surface energy) can grow. This LST criterion gives the instability criterion for a binary material as:

$$
\mathrm{D}_{\mathrm{L}}=\left(\frac{\mathrm{V}}{\mathrm{G}_{\mathrm{L}}}\right)_{\mathrm{C}} \frac{\Delta \mathrm{T}_{\mathrm{O}}\left(\mathrm{K}_{\mathrm{s}}+\mathrm{K}_{\mathrm{L}}\right) \mathrm{S}}{2 \mathrm{~K}_{\mathrm{L}}}
$$

where S (no units) is the Mullins-Sekerka stability constant [31], which is equal to one for low velocities; $\mathrm{K}_{\mathrm{L}}$ and $\mathrm{K}_{\mathrm{S}}\left(\mathrm{J} \mathrm{m}^{-1} \mathrm{~K}^{-1} \mathrm{~s}^{-1}\right)$ are the thermal conductivities for the fully solid and the fully liquid states, respectively. Note that the CUT model in Equation (10) and LST model in Equation (11) converge for the limit of $\mathrm{K}_{\mathrm{s}} \sim=\mathrm{K}_{\mathrm{L}}$.

A study by Burgeon et al. [38] with in situ interface imaging in microgravity conditions prevalent during the ordering of a cellular array structure concluded that the cause of interface dynamics and breakdown are more than just an account of the undercooled liquid ahead of the interface. An experimental study by Inatomi et al. [39] also cast doubt on whether an undercooled liquid or solute pile-up ahead of the interface is always present. They have argued persuasively that none of the theories for breakdown may be correct. For an interface's topographical instability in the case of facet prone materials, a strain accumulation model [34] has also been considered as describing the interface breakdown. However, Inatomi et al. [39] argue against a general strain model as the cause for the instability. In reference 1 , the variables $Z_{C U T}$ and $Z_{\text {LST }}$ were developed as parameters that describe the deviations from the experimental values. For the conditions where the interface instability occurs at high velocities, especially for very low alloy composition materials or with very low temperature gradients [1], both the CUT and LST models lose even more predictive capability [1,18]. Additionally, it should be noted the CUT and LST models do not address the facet/non-facet transitions or diffuseness at a molecular level, which is easily treated by the MEPR model [1,2].

\section{Comparison with Experiments for the Diffusion Coefficient Prediction}

The experimentally reported values of $\mathrm{D}_{\mathrm{L}}$ from non-solidification experiments for $\mathrm{Pb}-\mathrm{Sn}$ alloys at different concentrations are reported in [18] and are summarized in Table 1. The experimental $D_{L}$ values shown in Table 1 directly measured from non-solidification experiments are corrected by an Arrhenius-type correction for the liquidus temperature if the report is at a higher temperature than the liquidus [30-40]. However, note that these corrected numbers only impact the results in a minor way for the dilute alloy compositions considered. The results shown in Table 1 for the $D_{L}$ predictions for both CUT and LST show consistent and significant deviation from experimental measurements, as pointed out by De Cheveigne et al. [26] and Bensah et al. [18]. From Table 1, we note that the MEPR model shows stronger predictive capability of $\mathrm{D}_{\mathrm{L}}$ compared to CUT and LST for Pb-Sn alloys when compared with experimental values. However, even with the MEPR model, large deviations are noted for experimental conditions with a small temperature gradient. $\mathrm{Pb}-\mathrm{Sn}$ alloys are known to have very wide diffuse interfaces $[1,21,35-37]$. A lower $G_{S L I}$ dramatically influences the diffuse interface as noted above, and consequently the partition coefficient. The expectation that $k_{\text {eff }}$ approaches one with increased interface diffuseness is a reasonable assumption for dilute $\mathrm{Pb}-\mathrm{Sn}$ and icosahedral alloys with a diffuse interface $[32,33,40-48]$. Should $k_{\text {eff, }}$ therefore, change from 0.636 to 0.95 because of the low temperature gradient and diffuse interface, the $\mathrm{D}_{\mathrm{L}}$ value that is calculated is shown to become much lower to match the experimental data for even these low solidification temperature- gradient experiments. The corrected values are also shown in italics in Table 1 in the highlighted part of the table. Regardless, it should be noted that the assumed change in $k_{\text {eff }}$ to 0.95 is arbitrary and is only set to this number to illustrate the influence of the partition function on the calculated number. 
Table 1. A summary of results for $D_{L}$ in instability conditions for experimental breakdown compared with the value obtained from three instability models. Note that for MEPR, GSLI was assumed to be equal to $G_{\mathrm{L}}$ for the calculations. The diffusion data and physical constant from [18] for Pb-Sn alloys is $K s=33.6(\mathrm{~J} / \mathrm{mKs}), K_{L}=15.4(\mathrm{~J} / \mathrm{mKs})$; the equilibrium partition coefficient is $\mathrm{k}=\mathrm{k}_{\mathrm{eff}}=0.636$, $\mathrm{Tm}=600.65 \mathrm{~K}, \Delta h_{s l}=2.48 \times 10^{8}\left(\mathrm{~J} / \mathrm{m}^{3}\right)$. The shaded cells contain values of $\mathrm{D}_{\mathrm{L}}$ (in italics) for both cases (i.e., the equilibrium partition ration as well as when $\mathrm{k}_{\text {eff }}$ increases to 0.95 for the low temperature gradient conditions). MEPR Model: Circa 2011; LST Model: Circa 1964; CUT Model: Circa 1953.

\begin{tabular}{|c|c|c|c|c|c|c|c|c|c|}
\hline \multirow[t]{2}{*}{ Composition } & \multirow{2}{*}{$\begin{array}{c}\mathrm{D}_{\mathrm{L}}\left(\times 10^{-9}\right. \\
\left.\mathrm{m}^{2} / \mathrm{s}\right) \\
\text { at } \mathrm{T}_{1} \text { from } \\
\text { Experiment * }\end{array}$} & \multirow{2}{*}{$\begin{array}{c}\text { Imposed } \\
\mathrm{V}_{\mathrm{C}} \\
(\mathrm{m} / \mathrm{s}) \\
\times 10^{-6}\end{array}$} & \multirow{2}{*}{$\begin{array}{c}\text { Variable } \\
\qquad \begin{array}{c}\mathrm{G}_{\mathrm{L}} \\
(\mathrm{K} / \mathrm{m})\end{array}\end{array}$} & \multirow{2}{*}{$\begin{array}{l}\text { Alloy } \\
\text { Ts (K) }\end{array}$} & \multirow{2}{*}{$\begin{array}{c}\text { Variable } \\
\text { T1 (K) }\end{array}$} & \multirow{2}{*}{$\begin{array}{c}\mathrm{k}= \\
0.636 \\
\mathrm{k}=0.95\end{array}$} & \multicolumn{3}{|c|}{$\begin{array}{c}\mathrm{D}_{\mathrm{L}}\left(\times 10^{-9} \mathrm{~m}^{2} / \mathrm{s}\right) \text { at } \mathrm{T}_{\mathrm{S}} \text { from } \\
\text { Solidification Theories }\end{array}$} \\
\hline & & & & & & & $\begin{array}{l}\text { MEPR } \\
\text { Model } \\
\text { Upper } \\
\text { Bound }\end{array}$ & $\begin{array}{l}\text { CUT } \\
\text { Model }\end{array}$ & $\begin{array}{c}\text { LST } \\
\text { Model }\end{array}$ \\
\hline $\mathrm{Pb}-0.01 w t \% \mathrm{Sn}$ & 1.656 & 167 & 540 & 600.621 & 600.604 & 4.619 & 2.3095 & 5.398 & 8.587 \\
\hline $\mathrm{Pb}-0.03 w t \% \mathrm{Sn}$ & 1.655 & 73.5 & 820 & 600.560 & 600.508 & 4.016 & 2.008 & 4.692 & 7.465 \\
\hline $\mathrm{Pb}-0.05 w t \% \mathrm{Sn}$ & 1.654 & 73.5 & 1380 & 600.499 & 600.412 & 3.976 & 1.988 & 4.646 & 7.392 \\
\hline $\mathrm{Pb}-0.06 w t \% \mathrm{Sn}$ & 1.654 & 75.0 & 1220 & 600.469 & 600.364 & 5.507 & 2.7535 & 6.435 & 10.24 \\
\hline $\mathrm{Pb}-0.1 w t \% \mathrm{Sn}$ & 1.653 & 56.7 & 1200 & 600.347 & 600.172 & 7.053 & 3.5265 & 8.241 & 13.11 \\
\hline $\mathrm{Pb}-0.15 w t \% \mathrm{Sn}$ & 1.652 & 33.3 & 1300 & 600.194 & 599.933 & 5.733 & 2.8665 & 6.699 & 10.66 \\
\hline $\mathrm{Pb}-0.15 w t \% \mathrm{Sn}$ & 1.652 & 108 & 415 & 600.194 & 599.933 & $\begin{array}{c}58.24 \\
2.97\end{array}$ & $\begin{array}{l}29.12 \\
1.485\end{array}$ & 68.06 & 108.3 \\
\hline $\mathrm{Pb}-0.15 w t \% \mathrm{Sn}$ & 1.652 & 142 & 465 & 600.194 & 599.933 & $\begin{array}{c}68.34 \\
3.48\end{array}$ & $\begin{array}{c}34.17 \\
1.74\end{array}$ & 79.86 & 127.1 \\
\hline $\mathrm{Pb}-0.15 w t \% \mathrm{Sn}$ & 1.652 & 167 & 485 & 600.194 & 599.933 & $\begin{array}{c}77.06 \\
3.93 \\
\end{array}$ & $\begin{array}{c}38.53 \\
1.96\end{array}$ & 90.05 & 143.3 \\
\hline $\mathrm{Pb}-0.15 w t \% \mathrm{Sn}$ & 1.652 & 230 & 700 & 600.194 & 599.933 & $\begin{array}{c}73.54 \\
3.75\end{array}$ & $\begin{array}{c}36.77 \\
1.87\end{array}$ & 85.93 & 136.7 \\
\hline
\end{tabular}

\section{Summary Discussions}

Topographical and diffuse interface reconfigurations occur with a change in the solidification rate. In this article, we pursue the hypothesis that the interface configuration during solidification is determined by the maximum rate of entropy production in the region between a rigorous solid and rigorous liquid phase. We posit that when an interface begins to migrate, there are several stable configurations that are possible. These include atomically planar, diffuse-planar, facet non-planar, and cellular nonplanar configurations. The configuration and topographical condition that affords the maximum entropy production rate (MEPR) yields the most stable interface configuration. The principle of MEPR is applied to (1) describe atomically smooth and diffuse interfaces, (2) provide quantitative results for the diffuse interface thickness and the number of pseudo-atomic layers in the interface region, and (3) predict the transition from planar to a non-planar facet or non-facet cellular morphology as a function of solidification velocity or temperature gradient. The MEPR model provides for an assessment of the interface diffuseness at the breakdown condition. It also allows for the break down condition to be expressed in terms of the cooling rate and the entropy generation rate.

Numerous experimental investigations spanning sixty years have failed to comprehensively validate any of the existing solid-liquid interface (SLI) growth instability models. With the MEPR model for the first time, breakdown conditions are predicted with a fair degree of accuracy for several binary alloys, where no previous theoretical model had predictability. The model considers steady-state solidification at close-to-equilibrium and far-from-equilibrium conditions. For dilute $\mathrm{Pb}-\mathrm{Sn}$ alloys, the MEPR model gives closer $\mathrm{D}_{\mathrm{L}}$ predictions compared to the predictions made by the more traditional CUT and LST models. Regardless of the success of the model to date, it should be noted that the model remains untested for alloys with a significant amount of solute content. 
Author Contributions: Conceptualization, J.A.S.; methodology, J.A.S.; validation, Y.D.B. and J.A.S. formal analysis, Y.D.B. and J.A.S.; investigation, Y.D.B. and J.A.S.; resources, Y.D.B. and J.A.S.; data curation, Y.D.B.; writing - original draft preparation, Y.D.B. and J.A.S.; writing—review and editing, J.A.S.; visualization, Y.D.B.; supervision, J.A.S.; project administration, J.A.S.; funding acquisition, J.A.S. All authors have read and agreed to the published version of the manuscript.

Funding: The authors gratefully acknowledge support from MHI Inc., www.mhi-inc.com Cincinnati, Ohio for this ongoing research.

Conflicts of Interest: The authors declare no conflict of interest.

\section{Nomenclature and Abbreviations}

\section{Letter symbols}

Af

$A_{S L I}$

$\mathrm{B}$

$\mathrm{Cp}$

d

$\Delta \mathrm{C}_{\mathrm{O}}$

$\mathrm{D}$

fs

GS

$\mathrm{G}_{\mathrm{L}}$

$\mathrm{G}_{\mathrm{SLI}}$

$\Delta \mathrm{h}_{\mathrm{m}}$

$\Delta \mathrm{h}_{\mathrm{sl}}$

Js

k

$\mathrm{k}_{\text {eff }}$

$\Delta \mathrm{KE}$

KL

KS

$\mathrm{m}_{\mathrm{L}}$

M

N

Q

$R_{g}$

$\mathrm{S}$

$\mathrm{S}_{\mathrm{f}}$

$\dot{\mathrm{s}}_{\mathrm{E}}$

$\dot{s}_{\text {gen }}$

$\dot{s}_{\text {in }}$

$\dot{\mathrm{s}}_{\text {out }}$

$\dot{s}_{\text {gen }}$

$\dot{\mathrm{s}}_{\mathrm{LG}}$

$\left(S_{\text {gen }}\right)_{\text {max }}$

$d S_{c v} / d t$

$d s_{c v} / d t$

$\mathrm{t}$

Tli

Tsi

$\Delta \mathrm{T}_{\mathrm{SLI}}$

(dCLG/dz) or

$(\Delta \mathrm{CO} / \delta \mathrm{c})$

$\mathrm{Tm}$ area of a solute flux in a liquid $\left(\mathrm{m}^{2}\right)$

area of an interface in a solid-liquid region $\left(\mathrm{m}^{2}\right)$

Entropic contribution from the solute boundary layer

average heat capacity across a solid-liquid interface $\left(\mathrm{Jm}^{-3} \mathrm{~K}^{-1}\right)$

interplanar lattice spacing $(\mathrm{m})$

change in concentration at a solute distance $z\left(\right.$ mole m $\left.{ }^{-3}\right) \Delta \mathrm{C}_{\mathrm{O}}=\frac{\Delta \mathrm{T}_{\mathrm{O}}}{\mathrm{m}_{\mathrm{L}}}$

Diffusion Coefficient $\left(\mathrm{m}^{2} \mathrm{~s}^{-1}\right)$

fraction of liquid solidified at the solid-liquid interface (dimensionless)

temperature gradient in a solid $\left(\mathrm{Km}^{-1}\right)$

temperature gradient in a liquid $\left(\mathrm{Km}^{-1}\right)$

linear temperature gradient across a diffuse interface $\left(\mathrm{Km}^{-1}\right)$

heat of fusion of a solid with defects $\left(\mathrm{Jm}^{-3}\right)$

equilibrium heat of fusion $\left(\mathrm{Jm}^{-3}\right)$ or $\left(\mathrm{Jmol}^{-1}\right)$

solute flux in a liquid entering a solid-liquid interface (mole $\mathrm{s}^{-1}$ )

equilibrium partition coefficient obtained from the phase diagram (dimensionless)

effective partition coefficient at a solid-liquid interface (dimensionless)

gain or loss in kinetic energy $(\mathrm{J})$

thermal conductivity for a rigorous liquid $\left(\mathrm{Jm}^{-1} \mathrm{~K}^{-1} \mathrm{~s}^{-1}\right)$

thermal conductivity for a rigorous solid $\left(\mathrm{Jm}^{-1} \mathrm{~K}^{-1} \mathrm{~s}^{-1}\right)$

slope of the equilibrium liquidus line at the SLI for a binary material $\left(\mathrm{Km}^{3} \mathrm{~mole}^{-1}\right)$

Entropic contribution from the thermal flow

Diffuseness contribution to the entropy generation

lost work potential from the heat generation from a solid-liquid interface (J)

molar gas constant $\left(\mathrm{Jmol}^{-1} \mathrm{~K}^{-1}\right)$

Mullins and Sekerka stability constant (dimensionless)

flux entropy rate $\left(\mathrm{JK}^{-1} \mathrm{~s}^{-1}\right)$

change in entropy generation rate density due to exchange of matter and energy to and

from a solid-liquid interface with its surrounding $\left(\mathrm{Jm}^{-3} \mathrm{~K}^{-1} \mathrm{~s}^{-1}\right)$

irreversible entropy generation rate in a diffuse region $\left(\mathrm{JK}^{-1} \mathrm{~s}^{-1}\right)$

rate of entropy entering a control volume $\left(\mathrm{JK}^{-1} \mathrm{~s}^{-1}\right)$

rate of entropy leaving a control volume $\left(\mathrm{JK}^{-1} \mathrm{~s}^{-1}\right)$

total irreversible entropy generated rate density at an interface $\left(\mathrm{Jm}^{-3} \mathrm{~K}^{-1}\right)$

entropy generation rate density by the solute gradient in a liquid $\left(\mathrm{Jm}^{-3} \mathrm{~K}^{-1}\right)$

maximum entropy generation due to lost work $\left(\mathrm{JK}^{-1}\right)$

total steady state entropy rate in a control volume $\left(\mathrm{JK}^{-1} \mathrm{~s}^{-1}\right)$

total steady state entropy rate density in a control volume $\left(\mathrm{Jm}^{-1} \mathrm{~K}^{-1} \mathrm{~s}^{-1}\right)$

time (s)

liquidus temperature at a solid-liquid interface boundary $(\mathrm{K})$

solidus temperature at a solid-liquid interface boundary $(\mathrm{K})$

temperature difference across a solid-liquid interface $(\mathrm{K})$

change in solute gradient in a liquid (mole $\mathrm{m}^{-4}$ )

melting temperature $(\mathrm{K})$ 
Tav average temperature between Tli and Tsi across a diffuse interface (K)

$\Delta \mathrm{T}_{\mathrm{O}} \quad$ solidification temperature range $(\mathrm{K})$

$\mathrm{V} \quad$ solidification interface velocity $\left(\mathrm{ms}^{-1}\right)$

$\mathrm{W}_{\mathrm{L}} \quad$ lost work (J)

$\mathrm{dz}$ or $\delta \mathrm{c} \quad$ change in the position length of the solute $(\mathrm{m})$

$\mathrm{Z}_{\mathrm{CUT}} \quad$ deviation parameter of CUT from experiment at breakdown (dimensionless)

$Z_{\mathrm{LST}} \quad$ deviation parameter of LST from experiment at breakdown (dimensionless)

\section{Greek symbols}

$\Omega$ flux volume $\left(\mathrm{m}^{3}\right)$

$\Delta \Omega S \quad$ volume shrinkage $\left(\mathrm{m}^{3}\right)$

$\delta_{\mathrm{C}} \quad$ Solute boundary layer at the critical point $\delta_{C}=\frac{2 D_{L}}{V}(\mathrm{~m})$

$|\Delta \rho \mathrm{k}| \quad$ density shrinkage $\left(\mathrm{kgm}^{-3}\right)(\rho \mathrm{s}-\rho l)$

$\rho \mathrm{l} \quad$ density of rigorous liquid $\left(\mathrm{kgm}^{-3}\right)$

os density of rigorous solid $\left(\mathrm{kgm}^{-3}\right)$

$\Delta \mu_{\mathrm{c}} \quad$ Chemical potential difference $\left(\right.$ Jmole $\left.^{-1}\right)$

$\zeta \quad$ solid-liquid interface thickness $(\mathrm{m})$

$\omega_{\mathrm{D}} \quad$ energy of defects $\left(\mathrm{Jm}^{-3}\right)$

$\Omega_{\text {SLI }} \quad$ volume of a solid-liquid interface $\left(\mathrm{m}^{3}\right)$

$\dot{\varphi} \quad$ maximum entropy generation rate density for a moving interface $\left(\mathrm{Jm}^{-3} \mathrm{~K}^{-1} \mathrm{~s}^{-1}\right)$

$\eta_{\mathrm{G}} \quad$ driving force diffuseness (dimensionless)

$\eta_{\mathrm{T}} \quad$ total diffuseness (dimensionless)

$\eta_{\alpha} \quad$ thermal diffuseness (dimensionless)

Subscripts and acronyms

CUT constitutional undercooling theory circa 1953

LST linear stability theory circa 1964

MEPR maximum entropy production rate circa 2011

L liquid

S solid

LG solute gradients in the liquid

SG solute gradients in the solid

SLI solid-liquid interface

HD mean heat dissipation at the solid-liquid interface

f facet

nf non-facet

Expt experiment

\section{References}

1. Bensah, Y.D.; Sekhar, J.A. Interfacial instability of a planar Interface and diffuseness at the solid-liquid interface for pure and binary materials. arXiv 2016, arXiv:1605.05005.

2. Sekhar, J.A. The description of morphologically stable regimes for steady state solidification based on the maximum entropy production rate postulate. J. Mater. Sci. 2011, 46, 6172-6183. [CrossRef]

3. Sekhar, J.A.; Li, H.P.; Dey, G.K. Belousov-zhabotinsky nano-bands and nanoparticles. Acta Mater. 2010, 58, 1056-1073. [CrossRef]

4. Gershman, I.; Mironov, A.; Podrabinnik, P.; Kuznetsova, E.; Gershman, E.; Peretyagin, P. Relationship of secondary structures and wear resistance of antifriction aluminum alloys for journal bearings from the point of view of self-organization during friction. Entropy 2019, 21, 1048. [CrossRef]

5. Nosonovsky, M.; Bhushan, B. Thermodynamics of surface degradation, self-organization and self-healing for biomimetic surfaces. Philos. Trans. R. Soc. A 2009, 367, 1607-1627. [CrossRef]

6. Martyushev, L.M.; Seleznev, V.D.; Kuznetsova, I.E. Application of the principle of maximum entropy production to the analysis of the morphological stability of a growing crystal. Zh. Eksp. Teor. Fiz. 2000, 118, 149.

7. Bensah, Y.D.; Li, H.P.; Sekhar, J.A. The sgen rate maximization postulate: Applications to process-path analysis for solidification and micropyretic synthesis. Key Eng. Mater. 2012, 521, 79-86. [CrossRef] 
8. Nosonovsky, M. Self-organization at the frictional interface for green tribology. Philos. Trans. R. Soc. A 2010, 368, 4755-4774. [CrossRef]

9. Martyushev, L.M.; Seleznev, V.D. Maximum entropy production: Application to crystal growth and chemical kinetics. Curr. Opin. Chem. Eng. 2015, 7, 23-31. [CrossRef]

10. Veveakis, E.; Regenauer-Lieb, K. Review of extremum postulates. Curr. Opin. Chem. Eng. 2015, 7, 40-46. [CrossRef]

11. Poinsot, L. Théorie Nouvelle de la Rotation des Corps; Bachelier: Paris, France, 1834. (In French)

12. Sekhar, J.A. Tunable coefficient of friction with surface texturing in materials engineering and biological systems. Curr. Opin. Chem. Eng. 2018, 19, 94-106. [CrossRef]

13. Chung, B.J.; Vaidya, A. Non-equilibrium pattern selection in particle sedimentation. Appl. Math. Comput. 2011, 218, 3451-3465. [CrossRef]

14. Hill, A. Entropy Production as The Selection Rule Between Different Growth Morphologies. Nature 1990, 348, 426-428. [CrossRef]

15. Wang, W.; Zhang, Y.; Liu, J.; Wu, Z.; Li, B.; Sundén, B. Entropy generation analysis of fully developed turbulent heat transfer flow in inward helically corrugated tubes. Numer. Heat Transf. A-Appl. 2018, 73, 788-805. [CrossRef]

16. Ziegler, H.; Wehrli, C. On a principle of maximal rate of entropy production. J. Non-Equilib. Therm. 1978, 12, 229. [CrossRef]

17. Patela, R. Engineering Thermodynamics of Thermal Radiation for Solar Power Utilization; McGraw Hill: New York, NY, USA, 2010.

18. Bensah, Y.D.; Sekhar, J.A. Morphological assessment with the maximum entropy production rate postulate. Curr. Opin. Chem. Eng. 2014, 3, 91-98. [CrossRef]

19. Tiller, W.A.; Jackson, K.A.; Rutther, J.W.; Chalmers, B. The redistribution of solute atoms during the solidifications metals. Acta Met. 1952, 1, 428. [CrossRef]

20. Walton, D.; Tiller, W.A.; Rutter, J.W.; Winegard, W.C. Instability of a smooth solid-liquid interface during solidification. J. Met. AIME Trans. 1955, 205, 1023-1026. [CrossRef]

21. Winegard, W.C.; Chalmers, B. Supercooling and dendritic freezing in alloys. Trans. Am. Soc. Met. 1955, 47, 463-468.

22. Ruther, J.W.; Chalmers, B. A prismatic substructure formed during solidification of metals. Can. J. Phys. 1953, 31, 15-39. [CrossRef]

23. Sato, T.; Kenji, I.; Ohira, G. Interfacial stability of planar solid-liquid interface during unidirectional solidification of Al-Zn alloy. Trans. Jpn. Inst. Met. 1980, 21, 441-448. [CrossRef]

24. Kirkaldy, J.S. Entropy criteria applied to pattern selection in systems with free boundaries. Met. Trans. A 1985, 16, 1781-1796. [CrossRef]

25. Noel, N.; Jamgotchian, H.; Billia, B. In situ real-time observation of the formation and dynamics of a cellular interface in a succinonitrile- $0.5 \mathrm{wt} \%$ acetone alloy directionally solidified in a cylinder. J. Cryst. Growth 1997, 181, 117-132. [CrossRef]

26. De Cheveigne, S.; Guthmann, C.; Kurowski, P. Directional solidification of metallic alloys: The nature of the bifurcation from planar to cellular interface. J. Cryst. Growth 1988, 92, 616-628. [CrossRef]

27. Tiller, W.A.; Rutter, J.W. The effect of growth conditions upon the solidification of a binary alloy. Can. J. Phys. 1956, 34, 96-121. [CrossRef]

28. Shibata, K.; Sato, T.; Ohira, G. Morphological stabilities of planar solid-liquid interfaces during unidirectional solidification of dilute Al-Ti and Al-Cr alloys. J. Cryst. Growth 1978, 44, 419-434. [CrossRef]

29. Morris, I.R.; Winegard, W.C. The development of cells during solidification of a dilute $\mathrm{Pb}-\mathrm{Sb}$ alloy. J. Cryst. Growth 1969, 5, 361-375. [CrossRef]

30. Sato, T.; Ohira, G. The cellular breakdown of the planar interface in unidirectional solidification of Al-Cu alloy. Trans. Jpn. Inst. Met. 1971, 12, 285-294. [CrossRef]

31. Mullins, W.W.; Sekerka, R.F. Stability of a planar interface during solidification of a dilute binary alloy. J. Appl. Phys. 1964, 35, 444-451. [CrossRef]

32. Trivedi, R.; Kurz, W. Dendritic growth. Int. Mater. Rev. 1994, 39, 49-74. [CrossRef]

33. Kurz, W.; David, J.F.; Rohit, T. Progress in modelling solidification microstructures in metals and alloys: Dendrites and cells from 1700 to 2000. Int. Mater. Rev. 2019, 64, 311-354. [CrossRef] 
34. Dey, N.; Sekhar, J.A. Interface configurations during the directional growth of salol-I. morphology. Acta Met. 1993, 41, 409-424. [CrossRef]

35. Radojevic, V.; Nikolic, S.; Valcic, A. Interface shape and distribution of solute during vertical bridgeman growth of Al-Cu alloy. Mater. Lett. 2002, 52, 248-254. [CrossRef]

36. Fornaro, O.; Palacio, H.A.; Biloni, H. Segregation substructures in dilute Al-Cu alloys directionally solidified. Mater. Sci. Eng. A 2006, 417, 134-142. [CrossRef]

37. Grange, G.; Jourdan, C.; Gastaldi, J. In situ observation of synchrotron white beam X-ray topography of the solidification microstructures of an Al-0.73wt\% Cu Alloy. J. Cryst. Growth 1992, 121, 315-321. [CrossRef]

38. Bergeon, N.; Tourret, D.; Chen, L.; Debierre, J.M.; Guerin, R.; Ramirez, A.; Billia, B.; Karma, A.; Trived, R.I. Spatiotemporal dynamics of oscillatory cellular patterns in three-dimensional. Phys. Rev. Lett. 2013, 110, 1-5. [CrossRef]

39. Inatomi, Y.; Ashida, M.; Sakata, K.; Okutani, T. Simultaneous measurement of temperature and concentration during faceted cellular array growth under microgravity. World J. Eng. 2014, 11, 41-48. [CrossRef]

40. Sekhar, J.A.; Rao, P.V.; Trivedi, R. An icosahedral phase in the Pb-Bi system. Scr. Metall. 1987, $21,543-547$. [CrossRef]

41. Rao, P.V.; Sekhar, J.A. Lattice parameter measurements on rapidly pressurized Sn-Pb alloys. Mater. Lett. 1985, 3, 216-218. [CrossRef]

42. Sekhar, J.A.; Mantri, A.S.; Saha, S.; Balamuralikrishnan, R.; Rama Rao, P. Photonic, low-friction and antimicrobial applications for an ancient icosahedral/quasicrystalline nano-composite bronze alloy. Trans. Indian Inst. Met. 2019, 72, 2105-2119. [CrossRef]

43. Flemings, M.C. Solidification Processing; McGraw-Hill: New York, NY, USA, 1974; Chapter 8.

44. Sekhar, J.A. Evolution of solidification microstructures at high interface velocities. J. Cryst. Growth 1991, 109, 113-119. [CrossRef]

45. Burton, W.K.; Cabrera, N.; Frank, F. The growth of crystals and the equilibrium structure of their surfaces. Philos. Trans. R. Soc. A 1951, 243, 299-358. [CrossRef]

46. Cahn, J.W.; Hilliard, J.E. Free Energy of a nonuniform system I. Interface free energy. J. Chem. Phys. 1958, 28, 258-267. [CrossRef]

47. Landau, L. On the theory of phase transitions. Ukr. J. Phys. 1937, 11, 19-32. [CrossRef]

48. Jackson, K.A.; Uhlmann, D.R.; Hunt, J.D. On the nature of crystal growth from the melt. J. Cryst. Growth 1967, 1, 1-36. [CrossRef] 